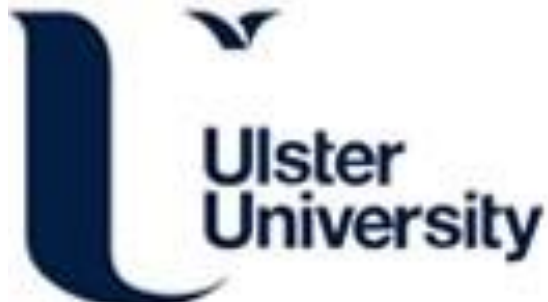

\section{Corona discharge-induced functional surfaces of polycarbonate and cyclic olefins substrates}

Haq, A., Boyd, A., Acheson, J., McLaughlin, J., \& Meenan, BJ. (2019). Corona discharge-induced functional surfaces of polycarbonate and cyclic olefins substrates. Surface and Coatings Technology, 362, $185-190$. https://doi.org/10.1016/j.surfcoat.2019.01.073

Link to publication record in Ulster University Research Portal

\section{Published in:}

Surface and Coatings Technology

Publication Status:

Published (in print/issue): 25/03/2019

DOI:

10.1016/j.surfcoat.2019.01.073

\section{Document Version}

Author Accepted version

\section{General rights}

Copyright for the publications made accessible via Ulster University's Research Portal is retained by the author(s) and / or other copyright owners and it is a condition of accessing these publications that users recognise and abide by the legal requirements associated with these rights.

\section{Take down policy}

The Research Portal is Ulster University's institutional repository that provides access to Ulster's research outputs. Every effort has been made to ensure that content in the Research Portal does not infringe any person's rights, or applicable UK laws. If you discover content in the Research Portal that you believe breaches copyright or violates any law, please contact pure-support@ulster.ac.uk. 


\section{Accepted Manuscript}

Corona discharge-induced functional surfaces of polycarbonate and cyclic olefins substrates

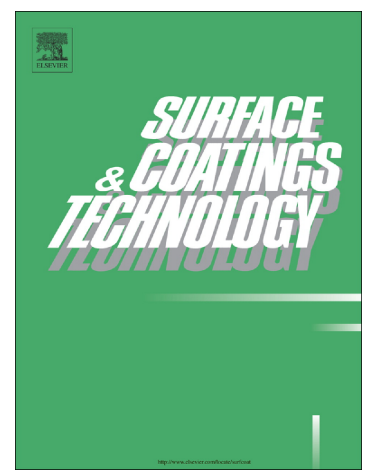

Atta ul Haq, Adrian Boyd, Jonathan Acheson, James McLaughlin, Brian J. Meenan

PII: S0257-8972(19)30079-9

DOI: https://doi.org/10.1016/j.surfcoat.2019.01.073

Reference: SCT 24272

To appear in: Surface \& Coatings Technology

Received date: 21 August 2018

Revised date: 17 January 2019

Accepted date: 18 January 2019

Please cite this article as: A. ul Haq, A. Boyd, J. Acheson, et al., Corona discharge-induced functional surfaces of polycarbonate and cyclic olefins substrates, Surface \& Coatings Technology, https://doi.org/10.1016/j.surfcoat.2019.01.073

This is a PDF file of an unedited manuscript that has been accepted for publication. As a service to our customers we are providing this early version of the manuscript. The manuscript will undergo copyediting, typesetting, and review of the resulting proof before it is published in its final form. Please note that during the production process errors may be discovered which could affect the content, and all legal disclaimers that apply to the journal pertain. 


\title{
Corona Discharge-induced Functional Surfaces of Polycarbonate and Cyclic Olefins Substrates
}

Atta ul Haq, Adrian Boyd, Jonathan Acheson, James McLaughlin and Brian J. Meenan

\begin{abstract}
Functional surfaces have great significance for improving the performance of bio-devices. The selection of appropriate ways to functionalise the surfaces of the polymers used for biodevices are in great demand. In particular, cyclic olefin copolymer (COC) and cyclic olefin polymers (COP) are emerging substrates for bio-devices and possess superior chemical resistance than other polymeric substrates such as polycarbonate (PC). These polymer substrates often require surface modification to provide the functionality required. Here, we present a means to functionalise the surfaces of these polymers by a corona discharge treatment method. The water contact angle (WCA) of as received PC, COC and COP was found to be around $80^{\circ}, 96^{\circ}$ and $93^{\circ}$, respectively. The WCA of PC, COC and COP is reduced by $40 \%, 46 \%$ and $44 \%$ when treated with corona dose of $95 \mathrm{Wmin} / \mathrm{m}^{2}$. The WCA of PC, $\mathrm{COC}$ and $\mathrm{COP}$ was further reduced by increasing the corona dosage. The reduction of WCA is found mainly due to the incorporation of oxygen-related functionalities (such as carboxylic, carbonyl or aldehyde groups) as confirmed by high-resolution X-ray photoelectron spectroscopy (XPS) and Time-of-flight secondary mass spectrometry (ToFSIMS). The oxygen to carbon $(\mathrm{O} / \mathrm{C})$ ratio is clearly increased after the corona treatment confirming the depletion of carbon on the functional surfaces. The functionality of surfaces obtained by corona treatment could be useful in the development of new bio-devices.
\end{abstract}

\section{Introduction}

Functional surfaces are of great significance in surface science and engineering as they can provide a platform for tailored bio-applications [1-3]. The functional attributes of a surface are, in the main, attributed to the molecular structure of the chemical groups present on the surface. These molecular structures at the surface are responsible for modifying the surface properties of the material such as wettability. The wettability of the surface is hence dependent on the type and chemical composition of the functionalities present on the surface. 
The use of appropriate polymeric materials could be an alternative to the glass substrates commonly used in biomedical industry. As such, polymer materials such as polycarbonate (PC), cyclic olefins copolymers (COC) and cyclic olefins polymers (COP) have gained tremendous interest in scientific community due to their optical transparency and low cost of mass production. COC and COP systems belong to olefins family and the main difference between them is the way they are synthetically produced. COC are synthesized through the polymerization of ethene and cyclic olefin monomer, i.e. norbornene while COP is produced through ring opening polymerization of the norbornene monomer [4][5]. COC often comes with the trade names of TOPAS and APEL while COPs are often represented with their tradenames like ZEONOR and ZEONEX [4]. Furthermore, the chemical stability of COC and COP make them promising materials in bio-applications [4]. However, highly inert polymeric materials such $\mathrm{PC}, \mathrm{COC} /$ and $\mathrm{COP}$ are very rarely used in their pristine form in bio-applications because of non-functional nature of their surfaces.

Developing appropriate functionalities on $\mathrm{PC}, \mathrm{COC}$ and $\mathrm{COP}$ materials is of the utmost importance as these could potentially be applied in bio-devices. The surface chemistries can be manipulated by surface treatments ranging from conventional chemical functionalization methods (i.e. wet chemistry) to plasma processes. For instance, polymer surfaces have been modified by using plasma-based techniques [6-20], by laser treatments [21,22], by UV/ozone treatment [23-26] and by wet chemical methods [27,28]. Among these surface modification techniques, the atmospheric pressure plasma technique (commonly referred to as corona treatment in air) is an environmentally friendly, easy and effective means for changing the surface properties by modifying the surface chemistry of the materials surface. A corona discharge is an ionized form of gas that is formed between two electrodes due to the introduction of an applied electric field [29]. Corona discharges can be negative or positive, depending on the type of polarities of the electrodes and the conduction in the corona environment can be unipolar or bipolar [30]. A corona plasma discharge in air consists of excited/reactive species that react further to produce radical, ions and photons [29]. The use of a dielectric barrier layer in the corona region provides a form of plasma referred to as a dielectric barrier discharge (DBD) [31-36]. When they impact with a material, these radicals/ions can transfer their energy to the molecules at the surface, breaking chemical bonds and thereby creating reactive conditions for the attachment of functional groups.

There are very few reports on the effects of atmospheric pressure-based plasma treatments of PC, COC and COP. In the work to date, a fast (with few days) hydrophobic recovery has 
been seen in these samples [12,16-18]. To prolong or prevent the hydrophobic recovery, the plasma treated samples often undergo through an additional step of direct chemical functionalization [37]. Hence, it is desirable for any plasma-based process to induce functionalities on the surface of the polymer with relatively longer hydrophobic recovery times.

Herein, we report changes to the surface chemistries of PC, COC and COP substrates when treated by a corona discharge that is capable of inducing a permanent change to their surface chemistry without the need for a supplementary functionalisation step. Furthermore, the evolution of the surface functionalities created by this method and their effect on changing the wettability of PC, COC and COP surfaces are investigated over a period of two weeks and correlated with surface chemistry, as determined by x-ray photoelectron spectroscopy (XPS) measurements. The water contact angle (WCA), a measure of surface wettability, was found to decrease with $\mathrm{O} / \mathrm{C}$ ratio and although there is some initial hydrophobic recovery, permanent changes to surface chemistry are induced. The plasma induced changes in the surface chemistries that lead to the changes in the water contact angle (WCA) produced here could be useful for choosing substrates for specific bio-device applications.

\section{Materials and Methods}

\subsection{Plasma treatment of polymer samples}

Polycarbonate (PC), cyclic olefin copolymer (COC) and cyclic olefin polymer (COP) sheets with a thickness of $2 \mathrm{~mm}$ were purchased from microfluidic ChipShop (Germany). These polymer substrates were then treated in air using a corona discharge generator (Arcotec $\mathrm{GmbH}$, Germany). The corona discharge system consists of treatment station that comprises three electrodes which are separated by a dielectric material and connected to a high frequency generator. The spacing between each of these top electrodes was kept at around 50 mm. A planar grounded electrode with a dielectric covering is used as movable stage for enhancing uniformity of the corona treatment. The sample to be treated is placed on the stage and the spacing from the top electrodes to the sample set at $\sim 6 \mathrm{~mm}$. The electrodes are supplied with a high voltage triggered at $25-50 \mathrm{kHz}$ frequency to create the DBD conditions. The treatment time was optimized for 10 cycles (approx. $1 \mathrm{~min}$ ) and the lift length (moving distance of stage) of $740 \mathrm{~mm}$. The corona dosage can be expressed by the following relationship [38,39]; 


$$
\mathrm{P}=\mathrm{D} \times \mathrm{W} \times \mathrm{V}
$$

Where $P$ is the generator power $(\mathrm{W}), D$ is the corona dosage $\left(\mathrm{Wmin} / \mathrm{m}^{2}\right), w$ is the width of the web (m) and $v$ is the speed of the web $(\mathrm{m} / \mathrm{min})$. The width of the web and the its speed of movement was $0.025 \mathrm{~m}$ and $20 \mathrm{~m} / \mathrm{min}$, respectively. Optimized DBD corona dosages of around $95 \mathrm{Wmin} / \mathrm{m}^{2}$ and $238 \mathrm{Wmin} / \mathrm{m}^{2}$ at ambient temperature and at humidity of around 55 $\%$ were used to treat the various polymer substrates.

\subsection{Chemical composition analysis}

X-ray photoelectron spectroscopy (XPS) was used to investigate the chemical composition of polymer samples before and after the plasma treatment. A Kratos Axis Ultra DLD spectrometer operating with an $\mathrm{Al} \mathrm{K}_{\alpha}$ X-ray source were used for this chemical characterization. High-resolution spectra for the C1s (280 to $295 \mathrm{eV}$ ) and O1s (525 to 540 $\mathrm{eV}$ ) regions were collected at a pass energy of $40 \mathrm{eV}$. The main component of the $\mathrm{C} 1 \mathrm{~s}$ the signal was calibrated to $284.8 \mathrm{eV}$. Casa XPS software was used to peak fit the XPS spectra and generate the associated quantitative data. The elemental and molecular ions present at surface of the polymer substrates were further characterized by using time of flight secondary ion spectroscopy (ToF-SIMS). The details of ToF-SIMS IonToF 5 instrument (IonToF, Germany) and the operating parameters employed are provided in the Supplementary Information.

\subsection{Water contact angle measurement}

The water contact angle (WCA) of the polymer substrates were measured using CAM 200 optical contact angle meter connected with a CCD camera and automated syringe driver. A 2 $\mu \mathrm{L}$ drop of water was delivered onto the surfaces and the WCA was obtained from a total of six measurements across the substrate. As there is no known significant correlation between the recovery in WCA and the applied corona dose, only the chemical changes induced by the $95 \mathrm{Wmin} / \mathrm{m}$ plasma dosage is investigated in detail herein.

\subsection{Surface roughness measurement}


The surface roughness $(R a)$ of $\mathrm{PC}, \mathrm{COC}$ and $\mathrm{COP}$ samples before and after the plasma treatment were measured by using a Bruker Stylus Profilometer (DektakXT, Bruker, UK). The procedure for surface roughness measurement is based on the ISO 4288:1996. The length scanned of the sample was $2 \mathrm{~mm}$ with a profiler tip diameter of $2 \mu \mathrm{m}$ and the measurement duration was $30 \mathrm{~s}$. The load applied was kept constant for all samples at $1 \mathrm{mg}$. An average value of the $R a$ was taken from a total of 5-line measurements.

\section{Results}

Figure 1 shows the water contact angle (WCA) values measured before and after the corona treatment of as received PC, COC and COP substrates. Immediately after the corona treatment with a DBD dose of around $95 \mathrm{Wmin} / \mathrm{m}^{2}$, the water contact angle (WCA) is reduced from around $80^{\circ}$ to $45^{\circ}, 96^{\circ}$ to $51^{\circ}$ and $93^{\circ}$ to $52^{\circ}$ on PC, COC and COP substrates, respectively. The WCA of the $\mathrm{PC}, \mathrm{COC}$ and $\mathrm{COP}$ were reduced to $38^{\circ}, 39^{\circ}$ and $27^{\circ}$ when treating with a corona dosage of around $238 \mathrm{Wmin} / \mathrm{m}^{2}$, respectively.

Figure $2 \mathrm{a}$ shows the digital photographs of the water droplets $(2 \mu \mathrm{L}$ each) on the surface of the various polymer (PC, COC and $\mathrm{COP}$ ) substrates before and after the corona treatment (95 $\mathrm{Wmin} / \mathrm{m}^{2}$ ). The changes in the surface wettability can be clearly seen from the changes in the shape of the water droplet as depicted on each of the PC, COC and COP surfaces. Partial recovery of the more hydrophobic character of the original surfaces was seen after one week. This recovery continued over the two-week measurement period but the WCA did not return fully to the original (pristine) value for any of the substrate types. The hydrophobic recovery within one week for the COC sample were found to be minimal when compared to PC and COP. The nature of the hydrophobic recovery noticed after two weeks in all samples is much slower than the previously reported behaviour of such polymer substrates treated by other forms of corona or plasma treatment. For instance, a fast (within a week) hydrophobic recovery of DBD treated $\mathrm{PC}$ has been reported in the literature [17]. Furthermore, the rate of hydrophobic recovery is found to be much lower in COC and COP than that for PC samples. In general, the hydrophobic recovery rate of these polymer substrates is much higher, i.e. within few hours to few days in previously reported results when compared to the that observed for the samples treated here which take several weeks to get close to original surface properties. 


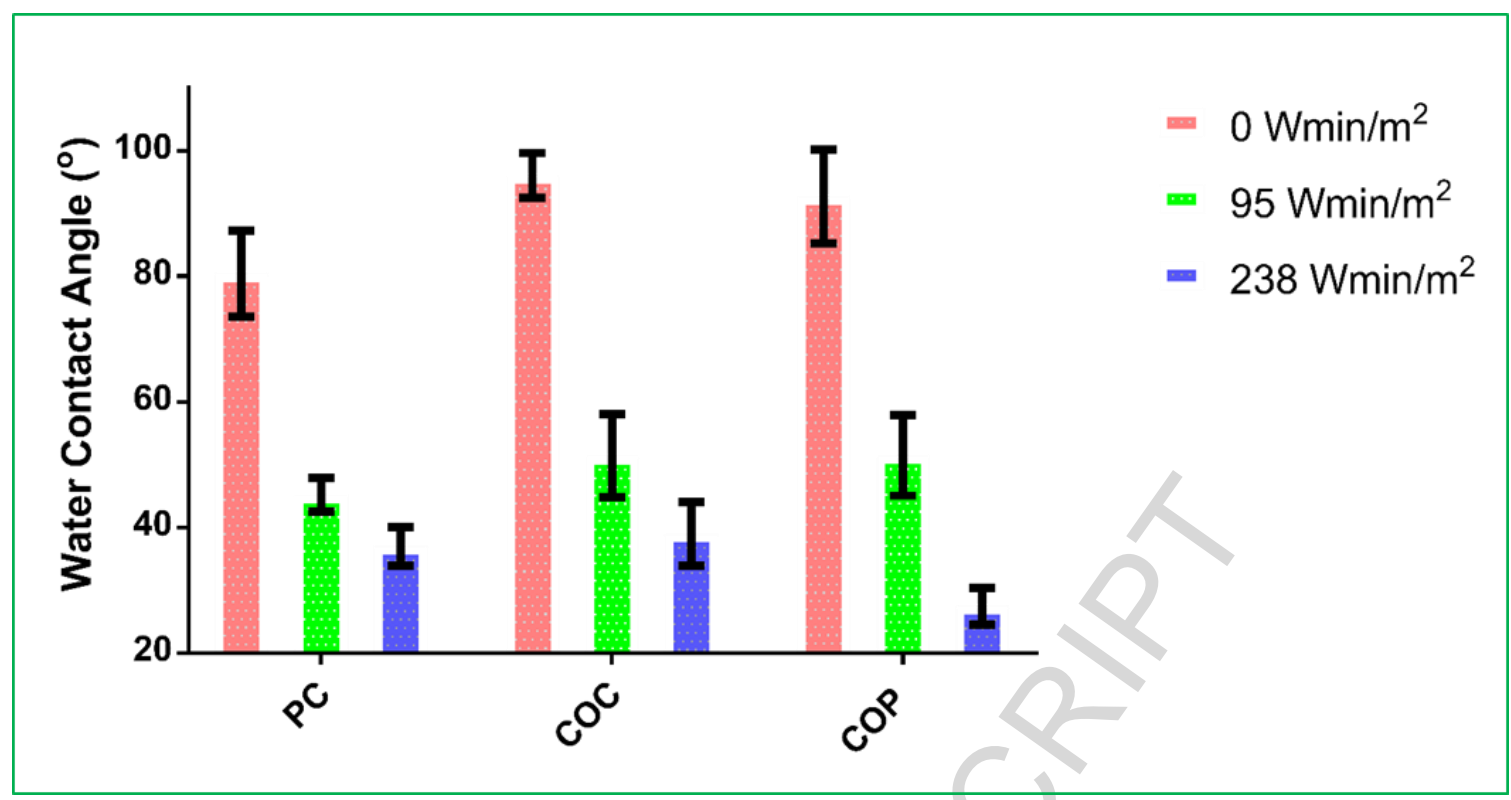

Figure 1: The water contact angle of as received and corona treated $P C, C O C$ and COP samples. The increase in corona dose has resulted reduction in the water contact angle in all samples. 


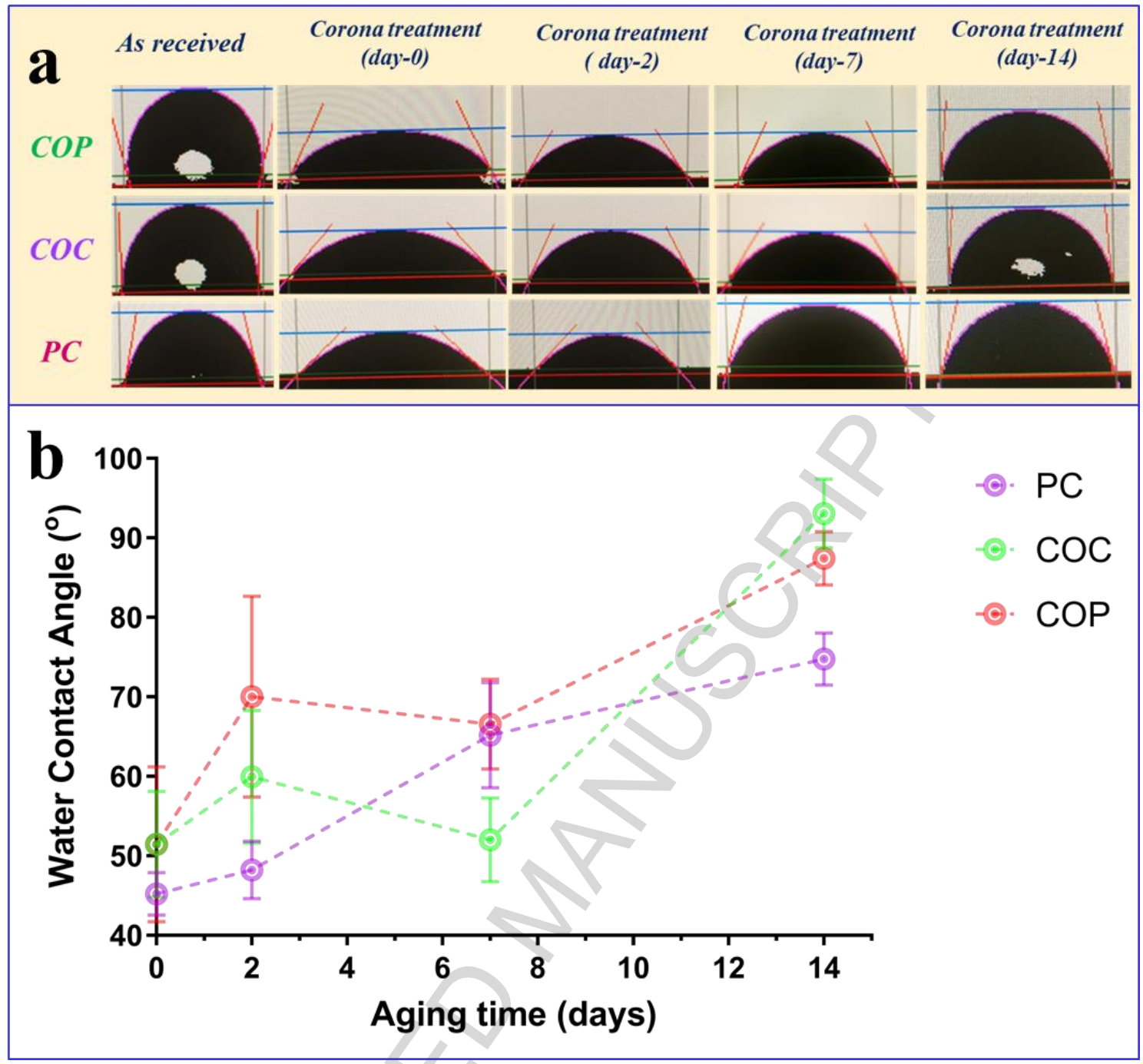

Figure 2: (a) The digital photographs of water droplet on the surface of polycarbonate $(P C)$, cyclic olefin copolymer (COC), cyclic olefin polymer (COP) before (as received) and after plasma (corona discharge) treatment (0,2, 7 and 14 days); (b) the water contact angle (in degrees) of as before and after plasma treatment of PC, COC and COP substrates.

The average surface roughness $\left(R_{a}\right)$ of as received PC, COC and COP samples were 0.067 $\mu \mathrm{m}, 0.083 \mu \mathrm{m}, 0.072 \mu \mathrm{m}$ respectively. After treatment, the $R_{a}$ values increased to $0.176 \mu \mathrm{m}$, $0.272 \mu \mathrm{m}, 0.234 \mu \mathrm{m}$ for PC, COC and COP, respectively (see Supplementary Information Figure S1).

Figure 3 represents the deconvoluted (peak fitted) $\mathrm{C} 1 s$ spectra for $\mathrm{PC}, \mathrm{COC}$ and COP samples before and after the corona treatment. Figure 3a shows the characteristic peaks $(\mathrm{C}$ $\mathrm{C} / \mathrm{C}-\mathrm{H}, \mathrm{C}-\mathrm{O},-\mathrm{O}-\mathrm{C}=\mathrm{O}-$ ) of the as received $\mathrm{PC}$ which are then modified after the plasma treatment by the addition of additional peaks like $\mathrm{COH}$ and $\mathrm{COOH}$, as shown in Figure $3 \mathrm{~b}$. Figure $3 \mathrm{c}$ and Figure $3 \mathrm{e}$ represents the distinct aliphatic and aromatic carbons in the as 
received $\mathrm{COC}$ and $\mathrm{COP}$ samples, respectively. Clearly, the introduction of additional oxygen functionalities $(\mathrm{C}-\mathrm{O}, \mathrm{COH}, \mathrm{COOH}$, and $\mathrm{C}=\mathrm{O})$ on $\mathrm{COC}$ and $\mathrm{COP}$ samples post plasma treatment can be seen in Figure $3 \mathrm{~d}$ and in Figure 3f, respectively.

The time-dependent changes in the percentage atomic concentration (\%At conc.) of $\mathrm{C}, \mathrm{O}, \mathrm{C}$ $\mathrm{C} / \mathrm{C}-\mathrm{H}$ and oxygenated functional species $(\mathrm{C}-\mathrm{O}, \mathrm{COH}, \mathrm{COOH}, \mathrm{C}=\mathrm{O}, \mathrm{O}-\mathrm{C}=\mathrm{O})$ the surface chemistry of PC, COC and COP samples after the plasma treatment has also been monitored (see Supplementary Information Figure S2-4) and the relevant data summarized in Table 1-3. The \%At conc. of $\mathrm{C}$ in $\mathrm{PC}, \mathrm{COC}$ and $\mathrm{COP}$ samples decreases just after the plasma treatment and then increases again with time, as can be in seen in Table 1-3 for the respectively. On the other hand, the concentration of oxygen in PC, COC and COP samples is increased just after the plasma treatment which is then decreased with time as shown in Table 1-3. Furthermore, the $\mathrm{O} / \mathrm{C}$ ratio is found to increase initially just after the plasma treatment but then decrease with time in all the samples.

The contribution of $\mathrm{C}-\mathrm{C} / \mathrm{C}-\mathrm{H}$ bonds in $\mathrm{PC} \mathrm{C} 1 s$ region is estimated to be around $88 \% \mathrm{At}$ which is then reduced to around $60 \%$ At just after the plasma treatment due to increase in the oxygen related functional species $(\mathrm{C}-\mathrm{O}, \mathrm{COH}, \mathrm{COOH}$ and $\mathrm{O}-\mathrm{C}=\mathrm{O})$, as shown in Table 1 . Over time, the \%At conc. of $\mathrm{C}-\mathrm{C} / \mathrm{C}-\mathrm{H}$ bonds increases which reflects the reduction in the concentration of oxygen related functional species. In COC and COP samples, the concentration of $\mathrm{C}-\mathrm{C} / \mathrm{C}-\mathrm{H}$ is around $100 \mathrm{At} \%$ which then reduces to $69 \mathrm{At} \%$ and $71 \mathrm{At} \%$ due to the addition of oxygen related functional species after plasma treatment, as shown in Table 2-3. Like the PC samples, the concentration of $\mathrm{C}-\mathrm{C} / \mathrm{C}-\mathrm{H}$ bonds in plasma treated $\mathrm{COC}$ and COP samples is increases with time, as shown in Table 2-3. 

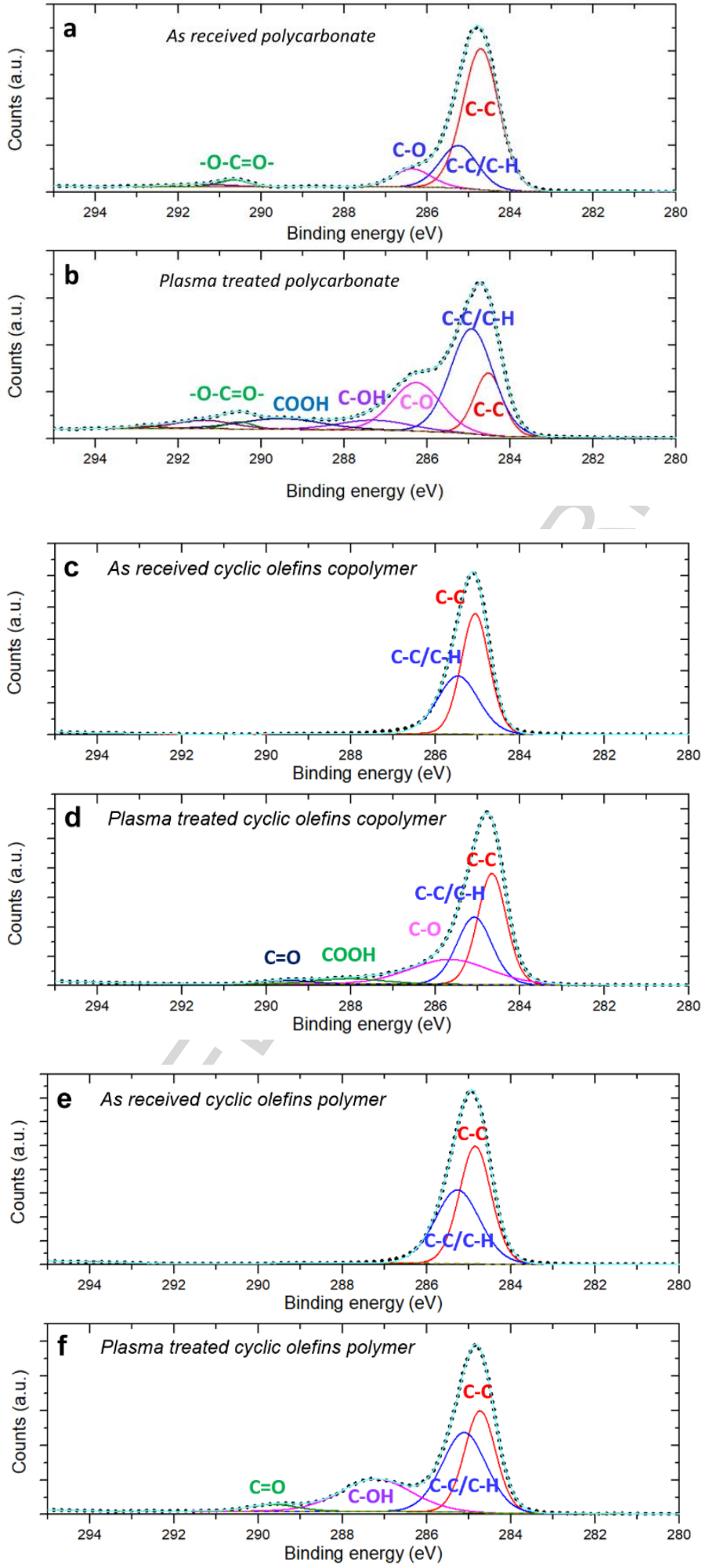

Figure 3: $(\boldsymbol{a}, \boldsymbol{c}, \boldsymbol{d})$ The high resolution deconvoluted (peak fitted) $C$ 1s spectra of as received polycarbonate (PC), cyclic olefins copolymer (COC) and cyclic olefins polymer (COP) respectively; $(\boldsymbol{b}, \boldsymbol{d}, \boldsymbol{f}) \mathrm{C} 1 \mathrm{~s}$ spectra of plasma treated $\mathrm{PC}, \mathrm{COC}$ and $C O P$ respectively. 
Table 1: A summary of the changes in the percentage atomic concentrations (\%At Conc.) of $C, O$ and the functional groups present before and after the plasma treatment of polycarbonate $(P C)$.

\begin{tabular}{|c|c|c|c|c|c|c|c|c|}
\hline & $\begin{array}{r}\text { C } \\
(\% \text { At } \\
\text { conc. })\end{array}$ & $\begin{array}{r}\mathbf{O} \\
(\% \text { At } \\
\text { conc. })\end{array}$ & $\begin{array}{c}\text { O/C } \\
\text { (\%At conc.) }\end{array}$ & $\begin{array}{c}C-C / C-H \\
(\% \text { At conc.) }\end{array}$ & $\begin{array}{c}C-O \\
\text { (\%At conc.) }\end{array}$ & $\begin{array}{c}\mathrm{C}-\mathrm{OH} \\
\text { (\%At conc.) }\end{array}$ & $\begin{array}{c}\mathrm{COOH} \\
\text { (\%At conc.) }\end{array}$ & $\begin{array}{l}-O-C=O- \\
\text { (\%At conc.) }\end{array}$ \\
\hline $\begin{array}{c}\text { As } \\
\text { received }\end{array}$ & 86.7 & 13.3 & 0.15 & 88.41 & 9.01 & - & - & 2.58 \\
\hline $\begin{array}{c}\text { plasma } \\
\text { treated-OD }\end{array}$ & 73.53 & 26.47 & 0.36 & 59.58 & 21.53 & 6.40 & 8.02 & 4.47 \\
\hline $\begin{array}{l}\text { Plasma } \\
\text { treated-2D }\end{array}$ & 77.51 & 22.49 & 0.29 & 75.94 & 9.73 & 7.29 & 2.99 & 4.05 \\
\hline $\begin{array}{c}\text { Plasma } \\
\text { treated- } \\
14 D\end{array}$ & 77.02 & 22.98 & 0.30 & 73.76 & 17.35 & $\nabla$ & 4.54 & 4.35 \\
\hline
\end{tabular}

Table 2: A summary of the changes in the concentrations of $C, O$ and the functional groups present before and after the plasma treatment of cyclic olefins copolymer (COC).

\begin{tabular}{|c|c|c|c|c|c|c|c|c|}
\hline & $\begin{array}{c}\mathbf{C} \\
\text { (\%At conc.) }\end{array}$ & $\begin{array}{c}0 \\
\text { (\%At conc.) } \\
\end{array}$ & $\begin{array}{c}O / C \\
\text { (\%At conc.) }\end{array}$ & $\begin{array}{l}\text { C-C/C-H } \\
\text { (\%At conc.) }\end{array}$ & $\begin{array}{c}\mathbf{C}-\mathbf{O} \\
(\% \text { At conc. })\end{array}$ & $\begin{array}{c}\mathrm{C}-\mathrm{OH} \\
(\% \text { At conc. })\end{array}$ & $\begin{array}{c}\mathrm{COOH} \\
\text { (\%At conc.) }\end{array}$ & $\begin{array}{c}C=O \\
\text { (\%At conc.) }\end{array}$ \\
\hline As received & 99.72 & 0.28 & 0.003 & 100 & - & - & - & - \\
\hline $\begin{array}{c}\text { plasma } \\
\text { treated-OD }\end{array}$ & 86.62 & 13.38 & & 69.1 & 24.1 & - & 4.56 & 2.24 \\
\hline $\begin{array}{c}\text { Plasma } \\
\text { treated-2D }\end{array}$ & 88.09 & 11.91 & 0.135 & 73.75 & 19 & - & 4.92 & 2.33 \\
\hline $\begin{array}{c}\text { Plasma } \\
\text { treated- } \\
14 D\end{array}$ & 90.52 & & 0.105 & 77.68 & 18.77 & - & 1.37 & 2.18 \\
\hline
\end{tabular}

Table 3: A summary of the changes in the concentrations of $C, O$ and the functional groups present before and after the plasma treatment of cyclic olefins polymer (COP).

\begin{tabular}{|c|c|c|c|c|c|c|c|c|}
\hline & $\begin{array}{r}\mathbf{C} \\
(\% \mathrm{At} \\
\text { conc. })\end{array}$ & $\begin{array}{r}\mathbf{O} \\
(\% \mathrm{At} \\
\text { conc. })\end{array}$ & $\begin{array}{l}\mathbf{O} \boldsymbol{C} \\
(\% \mathrm{At} \\
\text { conc. })\end{array}$ & $\begin{array}{c}\boldsymbol{C}-\mathrm{C} / \mathrm{C}-\boldsymbol{H} \\
\text { (\%At conc.) }\end{array}$ & $\begin{array}{c}\mathbf{C}-\mathbf{O} \\
\text { (\%At conc.) }\end{array}$ & $\begin{array}{c}\mathrm{C}-\mathrm{OH} \\
\text { (\%At conc.) }\end{array}$ & $\begin{array}{c}\mathrm{COOH} \\
\text { (\%At conc.) }\end{array}$ & $\begin{array}{l}\quad \boldsymbol{C}=\mathbf{O} \\
(\% \mathrm{At} \\
\text { conc. })\end{array}$ \\
\hline $\begin{array}{c}\text { As } \\
\text { received }\end{array}$ & 99.19 & 0.81 & 0.008 & 100 & - & - & - & - \\
\hline $\begin{array}{c}\text { plasma } \\
\text { treated-OD }\end{array}$ & 85.57 & 14.43 & 0.168 & 71.81 & - & 24.73 & - & 3.46 \\
\hline Plasma & 87.28 & 12.72 & 0.146 & 45.93 & 45.57 & - & - & 8.5 \\
\hline
\end{tabular}




\begin{tabular}{|c|c|c|c|c|c|c|c|c|}
\hline treated-2D & & & & & & & & \\
\hline $\begin{array}{c}\text { Plasma } \\
\text { treated- } \\
\mathbf{1 4 D}\end{array}$ & 90.06 & 9.94 & 0.110 & 78.84 & 16.98 & - & - & 4.18 \\
\hline
\end{tabular}

\section{Discussion}

There are two main factors that are responsible for changing the surface properties of polymeric materials, namely: surface roughness and surface chemistry. As the surface roughness induced due to the form of corona discharge treatment utilised here to modify the PC, COC and COP is not greatly changed, the dominant factor in controlling the surface properties (wettability) are then the changes in the surface chemistry. Although the surface roughness could be useful in tuning hydrophobicity or hydrophilicity in some patterned materials like discussed by Burton and Bhushan [2,40,41]. However, in our case, the role of surface roughness seems to be not influential than the surface chemistry. As shown by the XPS data in Figure 4 and the WCA data in Table 1-3, there is a reduction in the wettability as the $\mathrm{O} / \mathrm{C}$ ratio increases after plasma treatment of all the samples. This change in the surface chemistry of PC, COC and COP samples that is observed here is then due to the reaction of the reactive plasma (ions, radicals, ozone etc.) formed due to corona discharge in air. These reactive plasma species are capable of breaking the $\mathrm{C}-\mathrm{H}$ and or $\mathrm{C}-\mathrm{C}$ bonds in the topmost layers of the molecular structure of the polymers which then facilitates the attachment of polar functional groups, i.e. oxygen species. The effect of the plasma treatment process employed here (corona discharge) is then to introduce oxygen related surface functionalities like $\mathrm{C}-\mathrm{O}, \mathrm{COH}, \mathrm{COOH}$ and $\mathrm{C}=\mathrm{O}$ into the surface of the $\mathrm{PC}, \mathrm{COC}$ and $\mathrm{COP}$ samples. These changes to molecular structure of the surfaces have been confirmed by ToF-SIMS of the as received and corona treated $\mathrm{PC}, \mathrm{COC}$ and $\mathrm{COP}$ samples. The changes in the signal intensities of the prominent peaks detected in the ToF-SIMS analysis of PC, COC and COP in before and after the corona treatment (see Supplementary Information Figure S5-8) confirms the fragmentation and oxidation of the surfaces which supports the conclusion drawn from XPS as discussed above.

The introduction of polar groups into the polymer surface chemistry increases the surface energy as indicted by the reduction in the WCA presented earlier. The extent of the reduction of WCA depends on the corona dosage employed. A high dosage of corona increases the concentration of polar groups on the polymer surface and hence decreases the WCA, as seen 
in Figure 1. It is usual for the WCA of polymers to increases with time after the plasma treatment (hydrophobic recovery). Although hydrophobic recovery was observed in all of the samples treated in this work, it took a period of two weeks (see Figure 2) for this to occur in ambient air conditions and even then, the WCA was not that of the pristine surface. In general, hydrophobic recovery is deemed to be due to diffusion and re-orientation phenomena that occurs post processing [11,16,42-44]. Over time, the diffusion of smaller molecules into the bulk of the polymer reduces the surface energy and hence increases the WCA. Similarly, re-orientation of larger molecular chains on and just below the surface region changes the position of the polar groups over time such that their influence on the measured WCA lessens. Hence, after the plasma processing used in this work, the rise in the WCA over time is most likely to be initially due to the diffusion phenomenon, i.e. movement of the more reactive species into the sub-surface region while at later stages the re-orientation phenomenon dominates, i.e. the larger molecular fragments changing their position to face inwards relative to the surface plane.

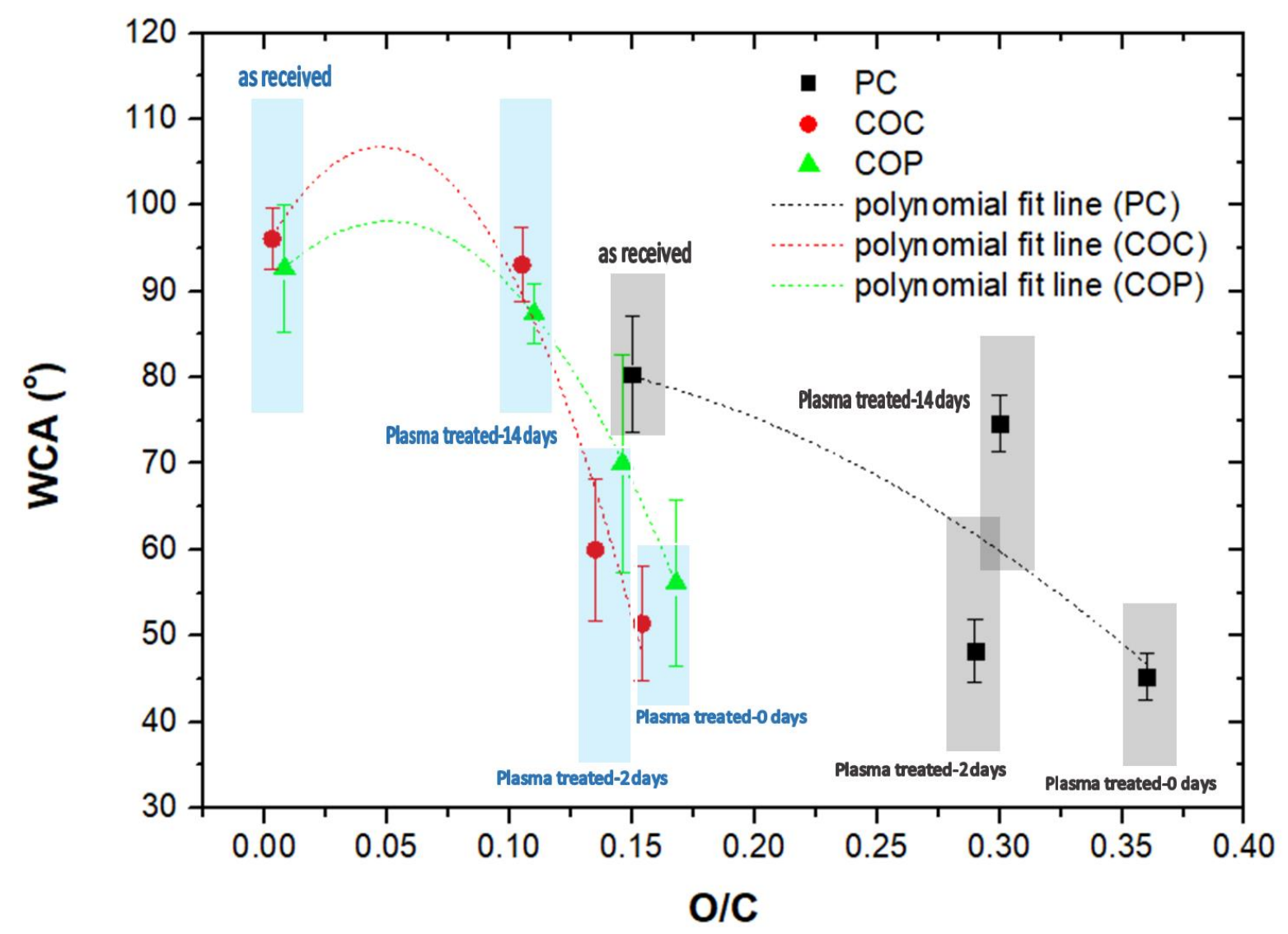

Figure 4: Plot of water contact angle (WCA) versus oxygen/carbon $(O / C)$ ratio in polycarbonate $(P C)$, cyclic olefins copolymer (COC) and cyclic olefins polymer (COP). 
Contrary to other plasma-based methods, the unique plasma treatment process used in this work and also previously used for other polymeric materials [32,33,35,36], yields functional surfaces with reduced surface damage due to the nature of the plasma and enhanced hydrophobic recovery time. A two-week recovery time is more than enough to facilitate surface events that can benefit from the modified surface function such as that needed for a bio-diagnostic assay. It is acknowledged that in many bio-device applications longer periods of hydrophobic recovery would be useful, and this could be attained by additional methods such as encapsulating the processed devices (e.g. in the case of microfluidics) or keeping the samples in inert atmosphere that would allow more time for bio-applications. Hence, overall the appropriate manipulation of the surface chemistries of PC, $\mathrm{COC}$ and $\mathrm{COP}$ can enable their use in the next-generation bio-devices.

\section{Conclusion}

Dielectric barrier discharge Corona treatment of PC, COC and COP performed in air has been found to result in enhanced wettability of their surfaces. Increased hydrophilicity of the $\mathrm{PC}, \mathrm{COC}$ and $\mathrm{COP}$ surfaces can be manipulated by changing the Corona dosage as observed in by the significant reduction in WCA of the polymer substrates. By monitoring changes in the surface chemistry and attendant wettability over time after the Corona treatment (dose: 95 $\mathrm{Wmin} / \mathrm{m}^{2}$ ) it is found that the hydrophobic recovery time is improved compared to previously reported surface modification methods. Moreover, only partial recovery was noticed in all samples over two weeks with a degree of residual permanent change recorded. Overall, the WCA in PC, COC and COP samples has been found to decrease with increasing the $\mathrm{O} / \mathrm{C}$ ratio. The change in $\mathrm{O} / \mathrm{C}$ ratio has been shown to be due to an increased oxidation of the polymer substrates that has been induced by the treatment. The effects of this type of DBD Corona induced functional change to the surfaces of PC, COC and COP could therefore be beneficial in next-generation biodevices.

\section{References}

[1] X. Yao, Y. Song, L. Jiang, Applications of bio-inspired special wettable surfaces, Adv. Mater. 23 (2011) 719-734. doi:10.1002/adma.201002689.

[2] M. Nosonovsky, B. Bhushan, Biologically inspired surfaces: Broadening the scope of 
roughness, Adv. Funct. Mater. 18 (2008) 843-855. doi:10.1002/adfm.200701195.

[3] J.J. Ramsden, D.M. Allen, D.J. Stephenson, J.R. Alcock, G.N. Peggs, G. Fuller, G. Goch, The Design and Manufacture of Biomedical Surfaces, CIRP Ann. - Manuf. Technol. 56 (2007) 687-711. doi:10.1016/j.cirp.2007.10.001.

[4] P.S. Nunes, P.D. Ohlsson, O. Ordeig, J.P. Kutter, Cyclic olefin polymers: Emerging materials for lab-on-a-chip applications, Microfluid. Nanofluidics. 9 (2010) 145-161. doi:10.1007/s10404-010-0605-4.

[5] L. Boggioni, I. Tritto, State of the art of cyclic olefin polymers, MRS Bull. 38 (2013) 245-251. doi:10.1557/mrs.2013.53.

[6] A.A. Ovtsyn, S.A. Smirnov, T.G. Shikova, I. V Kholodkov, Modification of polycarbonate surface in oxidizing plasma, J. Phys. Conf. Ser. 927 (2017) 012038. doi:10.1088/1742-6596/927/1/012038.

[7] A. Qureshi, S. Shah, S. Pelagade, N.L. Singh, S. Mukherjee, A. Tripathi, U.P. Despande, T. Shripathi, Surface modification of polycarbonate by plasma treatment, J. Phys. Conf. Ser. 208 (2010). doi:10.1088/1742-6596/208/1/012108.

[8] S.J. Hwang, M.C. Tseng, J.R. Shu, H. Her Yu, Surface modification of cyclic olefin copolymer substrate by oxygen plasma treatment, Surf. Coatings Technol. 202 (2008) 3669-3674. doi:10.1016/j.surfcoat.2008.01.016.

[9] H. Steffen, K. Schröder, B. Busse, A. Ohl, K.D. Weltmann, Functionalization of COC surfaces by microwave plasmas, Plasma Process. Polym. 4 (2007) 392-396. doi:10.1002/ppap.200731006.

[10] R.P. Gandhiraman*, C. Volcke, V. Gubala, C. Doyle, L. Basabe-Desmonts, C. Dotzler, M.F. Toney, M. Iacono, R.I. Nooney, S. Daniels, B. James, D.E. Williams, High efficiency amine functionalization of cycloolefin polymer surfaces for biodiagnostics, J. Mater. Chem. 20 (2010) 4116. doi:10.1039/b925737c.

[11] S. Roy, C.Y. Yue, Y.C. Lam, Z.Y. Wang, H. Hu, Surface analysis, hydrophilic enhancement, ageing behavior and flow in plasma modified cyclic olefin copolymer (COC)-based microfluidic devices, Sensors Actuators, B Chem. 150 (2010) 537-549. doi:10.1016/j.snb.2010.08.043.

[12] M.G. Katsikogianni, F.T. O’Neill, A. Davies, P. Mac Gabhann, D.P. Dowling, Use of atmospheric plasma jet treatments for the enhancement of cell adhesion to $1 \mathrm{~mm}$ internal diameter microwell cell arrays, 10th Int. Work. Biomed. Eng. BioEng 2011. 353 (2011) 1-4. doi:10.1109/IWBE.2011.6079038.

[13] C.B. Mello, K.G. Kostov, M. Machida, L. Rogério, O.D.O. Hein, Surface Modification of Polycarbonate by Atmospheric-Pressure Plasma Jets, 40 (2012) 2800-2805.

[14] F. Palumbo, R. Di Mundo, D. Cappelluti, R. Dagostino, SuperHydrophobic and SuperHydrophilic polycarbonate by tailoring chemistry and nano-texture with plasma processing, Plasma Process. Polym. 8 (2011) 118-126. doi:10.1002/ppap.201000098.

[15] K.A. Vijayalakshmi, M. Mekala, C.P. Yoganand, K. Navaneetha Pandiyaraj, Studies on modification of surface properties in polycarbonate (PC) film induced by DC glow discharge plasma, Int. J. Polym. Sci. 2011 (2011). doi:10.1155/2011/426057.

[16] R. Sharma, E. Holcomb, S. Trigwell, M. Mazumder, Stability of atmospheric-pressure 
plasma induced changes on polycarbonate surfaces, J. Electrostat. 65 (2007) 269-273. doi:10.1016/j.elstat.2006.10.001.

[17] K.G. Kostov, Y.A.A. Hamia, R.P. Mota, A.L.R. Dos Santos, P.A.P. Nascente, Treatment of polycarbonate by dielectric barrier discharge (DBD) at atmospheric pressure, J. Phys. Conf. Ser. 511 (2014) 0-6. doi:10.1088/1742-6596/511/1/012075.

[18] H. Yaghoubi, N. Taghavinia, Surface chemistry of atmospheric plasma modified polycarbonate substrates, Appl. Surf. Sci. 257 (2011) 9836-9839. doi:10.1016/j.apsusc.2011.06.034.

[19] V. Gubala, N.C.H. Le, R.P. Gandhiraman, C. Coyle, S. Daniels, D.E. Williams, Functionalization of cyclo-olefin polymer substrates by plasma oxidation: Stable film containing carboxylic acid groups for capturing biorecognition elements, Colloids Surfaces B Biointerfaces. 81 (2010) 544-548. doi:10.1016/j.colsurfb.2010.07.055.

[20] D. Nikolova, E. Dayss, G. Leps, A. Wutzler, Surface modification of cycloolefinic copolymers for optimization of the adhesion to metals, Surf. Interface Anal. 36 (2004) 689-693. doi:10.1002/sia.1737.

[21] J. Raj, G. Herzog, M. Manning, C. Volcke, B.D. MacCraith, S. Ballantyne, M. Thompson, D.W.M. Arrigan, Surface immobilisation of antibody on cyclic olefin copolymer for sandwich immunoassay, Biosens. Bioelectron. 24 (2009) 2654-2658. doi:10.1016/j.bios.2009.01.026.

[22] K. Bagga, R. McCann, F. O'Sullivan, P. Ghosh, S. Krishnamurthy, A. Stalcup, M. Vázquez, D. Brabazon, Nanoparticle functionalized laser patterned substrate: an innovative route towards low cost biomimetic platforms, RSC Adv. 7 (2017) 80608069. doi:10.1039/C6RA27260F.

[23] C.W. Tsao, L. Hromada, J. Liu, P. Kumar, D.L. DeVoe, Low temperature bonding of PMMA and COC microfluidic substrates using UV/ozone surface treatment, Lab Chip. 7 (2007) 499. doi:10.1039/b618901f.

[24] S. Roy, T. Das, C.Y. Yue, High performance of cyclic olefin copolymer-based capillary electrophoretic chips, ACS Appl. Mater. Interfaces. 5 (2013) 5683-5689. doi:10.1021/am401081d.

[25] R.O.F. Verkuijlen, M.H.A. Van Dongen, A.A.E. Stevens, J. Van Geldrop, J.P.C. Bernards, Surface modification of polycarbonate and polyethylene naphtalate foils by UV-ozone treatment and $\mu$ plasma printing, Appl. Surf. Sci. 290 (2014) 381-387. doi:10.1016/j.apsusc.2013.11.089.

[26] T.-Y. Lin, T.T. Pfeiffer, P.B. Lillehoj, Stability of UV/ozone-treated thermoplastics under different storage conditions for microfluidic analytical devices, RSC Adv. 7 (2017) 37374-37379. doi:10.1039/C7RA07435B.

[27] G. Godeau, S. Amigoni, T. Darmanin, F. Guittard, Post-functionalization of plasma treated polycarbonate substrates: An efficient way to hydrophobic, oleophobic plastics, Appl. Surf. Sci. 387 (2016) 28-35. doi:10.1016/j.apsusc.2016.06.053.

[28] F. Brisset, J. Vieillard, B. Berton, S. Morin-Grognet, C. Duclairoir-Poc, F. Le Derf, Surface functionalization of cyclic olefin copolymer with aryldiazonium salts: A covalent grafting method, Appl. Surf. Sci. 329 (2015) 337-346.

doi:10.1016/j.apsusc.2014.12.060. 
[29] D. Zhang, Q. Sun, L.C. Wadsworth, Mechanism of corona treatment on polyolefin films, Polym. Eng. Sci. 38 (1998) 965-970. doi:10.1002/pen.10264.

[30] M. Goldman, A. Goldman, R.S. Sigmond, The corona discharge, its properties and specific uses, Pure Appl. Chem. 57 (1985) 1353-1362. doi:10.1351/pac198557091353.

[31] R. Brandenburg, R. Brandenburg, Corrigendum: Dielectric barrier discharges : progress on plasma sources and on the understanding of regimes and single fi laments ( 2017 Plasma Sources, Plasma Sources Sci. Technol. 26 (2017) 053001.

[32] C.Z. Liu, J.Q. Wu, L.Q. Ren, J. Tong, J.Q. Li, N. Cui, N.M.D. Brown, B.J. Meenan, Comparative study on the effect of RF and DBD plasma treatment on PTFE surface modification, Mater. Chem. Phys. 85 (2004) 340-346. doi:10.1016/j.matchemphys.2004.01.026.

[33] C. Liu, N. Cui, N.M.. Brown, B.J. Meenan, Effects of DBD plasma operating parameters on the polymer surface modification, Surf. Coatings Technol. 185 (2004) 311-320. doi:10.1016/j.surfcoat.2004.01.024.

[34] C. Liu, N.M.D. Brown, B.J. Meenan, Statistical analysis of the effect of dielectric barrier discharge (DBD) operating parameters on the surface processing of poly(methylmethacrylate) film, Surf. Sci. 575 (2005) 273-286. doi:10.1016/j.susc.2004.11.026.

[35] D.J. Upadhyay, N.-Y.Cui, B.J. Meenan, N.M.D. Brown, The effect of dielectric barrier discharge configuration on the surface modification of aromatic polymers, $\mathrm{J}$. Phys. D. Appl. Phys. 38 (2005) 922. http://stacks.iop.org/0022-3727/38/i=6/a=022.

[36] C. Liu, N.M.D. Brown, B.J. Meenan, Uniformity analysis of dielectric barrier discharge (DBD) processed polyethylene terephthalate (PET) surface, Appl. Surf. Sci. 252 (2006) 2297-2310. doi:10.1016/j.apsusc.2005.04.016.

[37] S. Laib, B.D. MacCraith, Immobilization of biomolecules on cycloolefin polymer supports, Anal. Chem. 79 (2007) 6264-6270. doi:10.1021/ac062420y.

[38] M. Thomas, K.L. Mittal, Atmospheric Pressure Plasma Treatment of Polymers: Relevance to Adhesion, 2013. doi:10.1002/9781118747308.

[39] M. Kutz, Applied Plastics Engineering Handbook: Processing, Materials, and Applications: Second Edition, 2016.

[40] Z. Burton, B. Bhushan, Hydrophobicity, Adhesion, and Friction Properties of Nanopatterned Polymers and Scale Dependence for Micro- and Nanoelectromechanical Systems, Nano Lett. 5 (2005) 1607-1613. doi:10.1021/n1050861b.

[41] M. Nosonovsky, B. Bhushan, Roughness-induced superhydrophobicity: A way to design non-adhesive surfaces, J. Phys. Condens. Matter. 20 (2008). doi:10.1088/0953$8984 / 20 / 22 / 225009$.

[42] M. Lindner, N. Rodler, M. Jesdinszki, M. Schmid, S. Sängerlaub, Surface energy of corona treated PP, PE and PET films, its alteration as function of storage time and the effect of various corona dosages on their bond strength after lamination, J. Appl. Polym. Sci. 135 (2018) 45842. doi:10.1002/app.45842.

[43] E. Bormashenko, G. Chaniel, R. Grynyov, Towards understanding hydrophobic 
recovery of plasma treated polymers: Storing in high polarity liquids suppresses hydrophobic recovery, Appl. Surf. Sci. 273 (2013) 549-553.

doi:10.1016/j.apsusc.2013.02.078.

[44] M. Mortazavi, M. Nosonovsky, A model for diffusion-driven hydrophobic recovery in plasma treated polymers, Appl. Surf. Sci. 258 (2012) 6876-6883. doi:10.1016/j.apsusc.2012.03.122. 


\section{Corona Discharge-induced Functional Surfaces of Polymer Substrates}

\section{Highlights}

- Plasma (corona discharge) treated functional surfaces of Polycarbonate and cyclic olefins polymers were created.

- Drastic reduction in contact angle were observed with increasing the corona dosage.

- A correlation established between the surface chemistry and the contact angle. 